\title{
ONDERSKEIDING TUSSEN BEROEPSREALISTIESE EN -ONREALISTIESE ADOLESSENTE MET BEHULP VAN DIE WAARDESKAAL
}

\author{
R E ZEIER EN H J BRAND* \\ Eenheid vir Voorligtingsielkunde \\ Universiteit van Stellenbosch
}

\begin{abstract}
Differentiation between vocational realistic and unrealistic adolescents by means of a value scale. The usefulness of the Value Scale for distinguishing between adolescents with realistic or unrealistic approaches towards vocational choice was studied. A group of std. 10 pupils from a specific secondary school in the Cape Peninsula participated in the study. An evaluation with regard to the degree of realism of vocational decisions was made by three counselling psychologists. Classification of subjects was based on the agreement between their vocational choice, interest profiles, academic performance, intelligence test scores and course prerequisites. A number of variables were identified by discriminant analysis which distinguished significantly between realistic and unrealistic approaches. Value-preferences for realistic adolescents were more homogeneous and were globally interpreted as an intrinsic value pattern while subjects with unrealistic approaches showed a more differentiated pattern.
\end{abstract}

\section{OPSOMMING}

Die bruikbaarheid van die Waardeskaal vir die onderskeiding tussen beroepsrealistiese en beroepsonrealistiese adolessente is ondersoek deur ' $n$ groep st. 10-leerlinge uit ' $n$ spesifieke hoërskool in die Kaapse Skiereiland by die ondersoek te betrek. ' $n$ Evaluering met betrekking tot realisme van verklaarde loopbaankeuse is deur drie voorligtingsielkundiges gemaak op grond van ooreenstemming tussen verklaarde beroepskeuse, belangstellings, akademiese prestasie, verstandstoetstellings en kursusvoorvereistes. Beduidende verskille met betrekking tot werkwaardes is tussen die groepe met behulp van diskriminant-analise geïdentifiseer. Die waardevoorkeure van die beroepsrealistiese groep was meer homogeen van aard en kon globaal as intrinsieke waardevoorkeure beskryf word, terwyl die beroepsonrealistiese groep meer gedifferensieerde waardevoorkeurpatrone geopenbaar het.

Die waarde-opvattings en houdings van die moderne mens met betrekking tot die konsep "werk" verskil onderling en hou veral verband met die aard van ' $n$ individu se lewenstyl (Lindhard \& Africa, 1982). Die werksomgewing voorsien die individu van 'n werksidentiteit, terwyl die werklose persoon sy self-identiteit en doel in die lewe met reg kan bevraagteken (Tolbert, 1980).

Werkwaarde-oriëntasies kan ook in die nuwe Suid-Afrikaanse politieke en ekonomiese bestel 'n kritieke faktor word, veral teen die agtergrond van uitsprake soos die van Naicker (1994): "The western adherence to the Protestant work ethic, built on the premise that hard work is good for the individual, needs to be reviewed in the context of cultural transition currently taking place in South Africa" (p. 33).

Bloom, Hastings en Madus (in Whiteley \& Resnikoff, 1978) beweer dat ' $n$ waarde ' $n$ geïdentifiseerde, sosiale produk is wat gebruik word as 'n kriterium vir besluitneming, uiting van menings en motivering van optredes. Deur middel van waardevoorkeure word ' $n$ persoon se houdings en selfkonsep direk beïnvloed. Vir die doeleindes van hierdie studie word volstaan met die definisie van waardes deur Katz (1963) wat soos volg lui:

Values may be regarded as characteristic outer expressions and culturally influenced manifestations of needs. They are teleologically described in terms of the goal or the satisfaction that is sought rather than the motivating drive. They are often stated on different levels of complexity and abstraction (p. 16).

\section{KATZ SE MODEL}

Besluitnemingsteorieë verskaf ' $n$ sinvolle metode om die konseptualisering van beroepsgedrag wetenskaplik te beskryf (Crites, 1981). Met behulp van hierdie uitgangspunt is dit moontlik om ' $n$ individu se beroepskeuse-moontlikhede te ontleed, te oorweeg, te vergelyk en te toets sodat die kliënt maksimale voordeel uit die beroepsvoorligtingsproses kan trek (Fredrickson, 1982).

Volgens Katz (1963) is dit belangrik dat individue hul behoeftes moet identifiseer en hul waardes bepaal voordat realistiese beroepsbesluite geneem kan word, Katz (1963) het die loopbaankeuseproses soos volg ontleed:

- Die uitoefening van 'n loopbaankeuse word geïnspireer deur die kulturele sisteem wat ' $n$ besluit benodig en ' $n$ mate van teenstrydigheid tussen die kliënt se huidige stand van kenns of insig en die nodige en verlangde stand vir effektiewe besluitneming tot stand bring en handhaaf. Dit veroorsaak dus 'n onewewigtigheid;

- Die proses word aangedryf deur die individu se behoeftes en waardes asook deur sy voorgevoel dat sy behoeftes en waardes bevredig kan word by wyse van onderhandeling met die omgewing;

- Beroepsbesluitneming word bemiddel deur simbole wat die individu toelaat om sy beoordeling van gebeure uit die verlede te verplaas op verwagtinge vir die toekoms en hom in staat te stel om 'n nuwe rol te probeer sonder onherroeplike verbondenheid daaraan - dus word die toekoms in die huidige sielkundige omgewing ingebring;

- Effektiewe besluitneming word beïnvloed deur persoonlikheidseienskappe van individue (sowel as die uitwerking van sekere subkulture) en deur die uitoefening van keusemoontlikhede;

- Die beroepsbesluit word uitgeoefen sodra 'n nuwe ewewig gevestig is.

Katz (1963) se model ondersteun ook die ontwikkelingsperspektief in beroepsvoorligting wat beklemtoon dat ' $n$ individu 
voordurend betrokke is by ' $n$ opeenvolging van besluite, met - elke besluit wat beide daaropvolgende en vorige besluite beïnvloed. Deur van die selfkonsep as ' $n$ basis in loopbaanontwikkeling gebruik te maak, voer Katz aan dat ' $n$ individu se waardesisteem die hootaspek van die selfkonsep is en dus die belangrikste oortuigingskrag by beroepsbesluitneming vorm.

\section{WAARDES EN BEROEPSBESLUITNEMING}

Cooley (in Kroll, Dinklage, Lee, Morley \& Wilson, 1970) het bevind dat waardes die belangrikste veranderlike in die voorspelling van toekomstige loopbaankeuse van 'n groep laat adolessente was. Hilton (in Kroll et al., 1970), daarenteen, dui aan dat die waardes van jong volwassenes in sy steekproef baie vloeibaar was en geneig was om te verander soos wat hulle met ware loopbaanbesluite gekonfronteer is. Kotze (1993) het geen beduidende verskille ten opsigte van werkwaardes tussen akademies-suksesvolle en onsuksesvolle studente gevind nie.

Kanchier en Unruh (1989) het twee groepe, 'n groep wat van werk verander het asook ' $n$ groep wat nie van werk verander het nie, met mekaar vergelyk in ' $n$ poging om te probeer bepaal of die groepe van mekaar verskil met betrekking tot werkwaardes. Ook is probeer vasstel of geslagsverskille voorkom en of daar onderlinge verskille op verskillende bestuursvlakke bestaan. Stapsgewyse diskriminant-ontleding is op die totale steekproef ( 464 mans en vroue) uitgevoer. Die Work-Values Inventory is as meetinstrument gebruik. Gestandaardiseerde diskriminantfunksie-koëffisiënte en t-toets ontledings het getoon dat diegene wat van werk verander het, hoër tellings behaal het op kreatiwiteit, verskeidenheid, onafhanklikheid, prestasie en intellektuele stimulering, maar laer tellings op sekuriteit, ekonomiese vergoeding, kollegiale betrokkenheid, omgewing en prestige. Die groep vroue in die steekproef het van die totale steekproef asook van die groep mans verskil insoverre daar geen beduidende verskille gevind kon word met betrekking tot kreatiwiteit en prestasie ten opsigte van diegene wat van werk verander het en diegene wat nie van werk verander het nie. Senior bestuurders in die groep wat van werk verander het, het hoër tellings behaal op intellektuele stimulering as diegene wat nie van werk verander het nie.

Bestuurders wat nie van werk verander het nie, het ekonomiese vergoeding, status, prestige, gesag, sosiale interaksie en die samestelling van tyd hoog geag. In teenstelling daarmee het diegene wat van werk verander het, hoë waarde geheg aan vryheid, outonomie, vooruitgang, onafhanklikheid, genot en prestasie.

In 'n kruis-kulturele studie deur Vondracek, Shimizu, Schulenberg, Hostetler en Sakayanagi (1990) is bevind dat Japannese en Amerikaanse adolessente verskil met betrekking tot werkwaardes wat hulle hoog ag. Uit hierdie ondersoek het dit verder geblyk dat in die Japannese kultuur definitiewe geslagsverskille (wat op die geslagsrolstereotipes gebaseer is) bestaan. Japannese mans het beduidend hoër tellings as Japannese vroue op werkwaardes wat verband hou met gesag en onafhanklikheid behaal. Daarteenoor het die Amerikaanse vroue beduidend hoër tellings as die mans op kollegiale interaksie, altruïsme en omgewing behaal wat nie die geval was in die Japannese steekproef nie.

Rounds (1990) het ondersoek ingestel na die rol wat werkwaardes in werkstevredenheid speel. Sy steekproef het bestaan uit 106 mans en 119 vroue. Die resultate van die regressieontledings het daarop gedui dat werkwaardes ' $n$ beduidende proporsie $(29 \%)$ van die variansie verklaar het nadat vir die invloed van belangstellings gekontroleer is.

Kulturele waardes word moeilik onderskei van werkwaardes. Zunker (1990) verwys na die veranderde waardes in die Amerikaanse kultuur na die Tweede Wêreldoorlog as "verrysende waardes". Die tradisionele waarde "toekomsoriëntasie" (werk na doelwitte vir die toekoms) is grootliks deur ' $n$ verrysende waarde wat hy as "hedonisme" beskryf het, ver- vang. Hierdie oriëntasie word weerspieël in 'n nuwe fokus op die lewe vir die teenwoordige en huidige omdat die toekoms onbekend en onseker is. Alle werk word as tydelik waargeneem en min waarde word geheg aan die voortbestaan van die werk, werksidentiteit of die waarde van die werk self.

Wall (aangehaal in Zunker, 1990) beweer dat individue se waarde-oriëntasies sedert die vyftigerjare beduidende veranderinge ondergaan het. Die moontlikheid om "vertikaal" in 'n loopbaan bevordering te kry, "moving up the career ladder" (Zunker, 1990, p. 67), is uiters onseker in die huidige ekonomies onstabiele klimaat. Dit is onvermydelik dat wat die toekoms betref ook die aantal beskikbare loopbaangeleenthede sowel as eienskappe van die individu tydens die loopbaanvoorligtingsproses in aanmerking geneem behoort te word. Ekonomiese werklikhede beïnvloed nie slegs loopbaankeuses nie, maar ook hoe individue funksioneer in loopbane wat hulle nooit sou gekies het nie. Individuele persepsies van werk en gebondenheid aan werk is onlosmakend verbind aan ekonomiese en gemeenskapskragte. Individuele waardesisteme word altyd deur hierdie faktore beïnvloed en moet altyd in ag geneem word indien werkwaardes beoordeel word. "In essence, individuals evaluate their choices internally by considering values, interest, achievement, and experiences and externally by seeking acceptance and approval within the working environment" (Zunker, 1990, p. 80).

Zunker (1990) beweer verder . . . "as career counselors, we must be concerned with individual beliefs and values in the career decision-making process. An important function is to act as agents who provide methods for clarifying values" (p. 168).

\section{DOELSTELLING}

Die algemene doelstelling van hierdie studie was gevolglik om vas te stel watter van die subskale van die Waardeskaal (Langley, du Toit \& Herbst, 1992) beduidend diskrimineer tussen 'n groep beroepsrealistiese en beroepsonrealistiese adolessente, en om te bepaal of nuwe gevalle op grond van hulle prestasie op die subskale van die Waardeskaal as beroepsrealisties of beroepsonrealisties geklassifiseer kan word.

\section{STEEKPROEFNEMING}

Amptelike toestemming van die Kaaplandse Onderwysdepartement is verkry om leerlinge uit ' $n$ spesifieke hoërskool in die Kaapse Skiereiland by die ondersoek te betrek. Daar is besluit om slegs st. 10-leerlinge in die ondersoekgroep in te sluit, ten einde die groep so homogeen as moontlik te hou en om dit moontlik te maak dat die resultate van die huidige ondersoek tot die voordeel van die leerlinge aangewend kan word in die jaar waarin belangrike besluite met die oog op toekomstige loopbane geneem moes word. Matriekleerlinge is verder by die ondersoek betrek omdat die literatuur daarop dui dat ' $n$ individu se waardesisteem eers op ongeveer sewentienjarige ouderdom volkome ontwikkel het (Kohlberg, 1980).

Die steekproef het uit 208 subjekte bestaan, waarvan 128 en 80 onderskeidelik as beroepsrealisties en beroepsonrealisties geklassifiseer is. Daar was 104 seuns en 104 meisies. In die Afrikaanssprekende groep van 174, was 88 seuns en 86 meisies. Die Engelssprekende groep was heelwat kleiner en het uit 16 seuns en 18 meisies bestaan. Die hoërskool waaruit die steekproef afkomstig is, is geleë in 'n gegoede woonbuurt en as 'n model C-skool word relatief hoë jaarlikse skoolgelde van die leerlinge se ouers vereis. Die aanname kon dus gemaak word dat die steekproef redelik homogeen verteenwoordigend van die hoër sosio-ekonomiese statusgroep was.

Die gemiddelde intellektuele vermoëns van die seuns, gemeet in terme van die hoogste beskikbare tellings op die Nuwe SuidAfrikaanse Groeptoets (NSAGT), was 121; die gemiddelde vir die meisies was 119. Vir die totale groep was die gemiddelde 120. 


\section{VRAELYSTE}

\section{Die Waardeskaal}

Die eienskappe wat deur die Waardeskaal (Langley et al., 1992) gemeet word, kan eintlik beter as behoeftes beskryf word. Die Waardeskaal of WS (110 items) is ontwikkel om 'n persoon se behoefte aan elk van die volgende 22 fasette te meet: Vermoëbenutting, Prestasie, Vordering, Estetika, Altruïsme, Gesag, Outonomie, Kreatiwiteit, Kulturele identiteit, Finansiële beloning, Finansiële sekuriteit, Eie lewenstyl, Persoonlike ontwikkeling, Fisiese aktiwiteite, Liggaamlike vaardigheid, Prestige, Risiko, Sosiale interaksie, Sosiale verhoudinge, Geestelikheid, Verskeidenheid en Aangename werksomstandighede.

Die betroubaarheidskoëffisiënte van al die subskale van die WS is hoër as 0,73 , en twaalf subskale se betroubaarheidskoëffisiënte is 0,80 en hoër. Vir Engels- en Afrikaanssprekendes respektiewelik is die betroubaarheidskoëffisiënte van al die subskale hoër as 0,75 . Sewentien subskale vir Afrikaanssprekendes en sestien subskale vir Engelssprekende leerlinge se betroubaarheidskoëffisiënte is hoër as 0,80 . Vir persone wat Afrika-tale praat, is twintig subskale van die WS se betroubaarheidskoëffisiënte hoër as 0,70 , met slegs Geestelikheid $(0,68)$ en Verskeidenheid $(0,65)$ wat ietwat laer is. Die betroubaarheidskoëffisiënte van die WS kan as bevredigend beskou word indien die vraelys in die voorligtingspraktyk saam met ander relevante psigometriese instrumente gebruik word.

\section{B10-Belangstellingsvraelys}

Die B10-belangstellingsvraelys is ' $n$ verkorte weergawe van die KODUS-belangstellingsvraelys, wat deur die Sielkundige en Voorligtingsdiens van die Kaaplandse Onderwysdepartement, in samewerking met die Eenheid vir Studentevoorligting van die Universiteit van Stellenbosch, in 1978 vrygestel is. Die KODUS-belangstellingsvraelys is opgestel om die belangstellings van leerlinge en studente te meet, en dus as hulpmiddel by vakkeusevoorligting en beroepsvoorligting te dien. Die KODUS-belangstellingsvraelys bevat 220 items verteenwoordigend van twaalf belangstellingsvelde wat met breë beroepsrigtings ooreenstem. Die onderlinge verhoudings van die twaalf belangstellingsvelde word vir elke individuele leerling bepaal op grond van die aantal kere wat items van 'n spesifieke veld bo items van ander velde verkies word (Handleiding vir die KODUS-belangstellingsvraelys, 1984). Die KODUS-belangstellingsvraelys lewer dus ipsatiewe tellings wat ' $n$ individu se belangstellings rangorden.

\section{Biografiese Vraelys}

'n Vertroulike biografiese vraelys is opgestel met die doel om die volgende addisionele inligting vir die huidige ondersoek te verkry: Huistale van die subjekte en hul ouers, onderwyspeil van ouers, beroepe van ouers, vakprestasies en beroepskeuses van subjekte.

\section{PROSEDURE}

Die vraelyste is aan die einde van die tweede kwartaal 1992 op alle subjekte toegepas. Direk hierna is die subjekte versoek om ook die biografiese vraelys te voltooi. Subjekte moes hul beroepskeuse, kursuskeuse asook voorgenome opleidingsinstansie aandui.

'n Evaluering ten opsigte van elke subjek se realisme van beroepsvoorkeur is gemaak op grond van die leerlinge se verklaarde beroepskeuses, NSAGT-tellings (verkry vanaf leerlinge se kumulatiewe verslagkaarte), skolastiese prestasierekords en hulle B10-belangstellingsprofiele. Die evaluerings op grond waarvan subjekte as relatief realisties of onrealisties ten opsigte van beroepskeuse geklassifiseer is, is deur die huidige navorsers en twee voorligtingsielkundiges met onderskeidelik ses en agt jaar ervaring as beroepsvoorligters gemaak. Die gemiddeldes van hierdie beoordelings het gedien as gewigte waarvolgens die finale beoordelings gedoen is. Waar daar' $n$ teenstrydigheid tussen skolastiese aanleg, soos aangedui deur die NSAGT-tellings, en akademiese prestasie was, is voorkeur gegee aan akademiese prestasie as die beter voorspeller van toekomstige akademiese sukses.
Die realisme van beroepsvoorkeure word universeel bepaal op grond van die mate van ooreenstemming tussen beroepskeuses en faktore soos verstandsvermoë, skolastiese prestasie, belangstellings en sosio-ekonomiese bereikbaarheid (Osipow, 1983). Dit is aanvaar dat verdere opleiding binne almal se bereik sou wees omdat al die leerlinge in die huidige steekproef uit 'n hoë sosio-ekonomiese groep afkomstig was. 'n Leerling is as beroepsrealisties beskou indien daar ' $n$ hoë mate van ooreenstemming was tussen sy beroepsvoorkeur (kursuskeuse en opleidingsinstansie ingesluit) en skolastiese aanleg asook akademiese prestasie. Die keuse moes verder ook inpas by die primêre patroon wat in die belangstellingsprofiel na vore gekom het. Daar is ook bepaal of die leerling aan die nodige opleidingsvoorvereistes voldoen het wat vak- en graadkombinasies asook huidige prestasievlak (einde st. 9 en Junie st. 10) betref. 'n Gebrek aan sodanige ooreenstemming is beskou as ' $n$ aanduiding van ' $n$ beroepsonrealistiese benadering.

Standerd 10-leerlinge bevind hulle op grond van hul ouderdom in die oorgangstadium na volwassenheid, aldus Wijngaarden (aangehaal in Büchner, 1971). Juis omdat hulle in 'n oorgangstadium verkeer, sal ' $n$ aantal noodwendig nog beroepsonvolwasse, beroepsonseker en dus beroepsonrealisties wees. Hierdie onsekerheid mag dan ook verband hou met die onstabiliteit van die toekomsplanne van matrikulante.

\section{STATISTIESE TEGNIEKE}

Diskriminantontleding word gebruik om subjekte, op grond van ' $n$ aantal gemete onafhanklike veranderlikes, aan een van 'n aantal voorafbepaalde kategorieë toe te ken. Die toekenning geskied op so 'n wyse dat die waarskynlikheid van verkeerde klassifikasie minimaal is (Plug, Meyer, Louw \& Gouws, 1986).

Klecka (1986) beskryf diskriminant-ontleding soos volg: "Discriminant analysis is a statistical technique which allows the researcher to study the differences between two or more groups of objects with respect to several variables simultaneously" (p. 7).

Diskriminant-ontleding is dus 'n meerveranderlike statistiese tegniek wat gebruik kan word vir die identifisering van ' $n$ kombinasie van veranderlikes wat optimaal tussen twee of meer voorafgaande groepe sal onderskei, sowel as die bepaling van wiskundige formules op grond waarvan nuwe, ongeklassifiseerde gevalle aan die voorafbepaalde groepe toegewys kan word.

\section{RESULTATE}

Uit die totale aantal subjekte $(\mathrm{N}=208)$ is $128(61,5 \%)$ deur die beoordelingspaneel as beroepsrealisties en $80(38,5 \%)$ as beroepsonrealisties geklassifiseer. Die beroepsrealistiese groep het uit 55 seuns en 73 meisies bestaan, terwyl die beroepsonrealistiese groep uit 49 seuns en 31 meisies bestaan het. 'n Diskriminant-ontleding is uitgevoer ten opsigte van die data van die totale steekproef (beroepsrealisties teenoor beroepsonrealisties onderskeidelik).

Die gemiddeldes en standaardafwykings van die routellings van die onderskeie subgroepe ten opsigte van die verskillende waarde-dimensies verskyn in Tabel 1, en word grafies voorgestel in Figuur 1.

Die verkreë F-om-in-te-sluit-waardes wat vir elke veranderlike bereken is voordat enige veranderlike in die diskriminantfunksie ingesluit is, verskyn in Tabel 2.

Dit blyk uit Tabel 2 dat die veranderlike "kulturele identiteit" die grootste F-om-in-te-sluit-waarde gehad het. Hierdie veranderlike het dus die beste tussen die beroepsrealistiese en beroepsonrealistiese groepe onderskei, met $F(1,206)=10,521$, $p<0,01$. Hierdie veranderlike is gevolglik eerste in die diskriminant-funksie ingesluit. 
TABEL 1

- GEMIDDELDES $(\overline{\mathrm{X}})$ EN STANDAARDAFWYKINGS (S.A.) VAN DIE ROUTELLINGS OP DIE WS-SUBSKALE VIR DIE TOTALE STEEKPROEF

\begin{tabular}{|c|c|c|c|c|c|}
\hline \multirow[t]{2}{*}{ Veranderlikes } & & \multicolumn{2}{|c|}{$\begin{array}{l}\text { Beroeps- } \\
\text { realisties }\end{array}$} & \multicolumn{2}{|c|}{$\begin{array}{l}\text { Beroeps- } \\
\text { onrealisties }\end{array}$} \\
\hline & & $\bar{x}$ & s.a. & $\bar{x}$ & s.a. \\
\hline Vermoëbenutting & A1 & 18,5 & 1,8 & 17,9 & 2,0 \\
\hline Prestasie & A2 & 18,0 & 1,7 & 17,5 & 2,2 \\
\hline Vordering & $\mathrm{A} 3$ & 16,6 & 2,4 & 16,9 & 2,7 \\
\hline Estetika & A4 & 14,7 & 2,9 & 15,3 & 2,6 \\
\hline Altruïsme & A5 & 14,7 & 3,0 & 14,5 & 3,2 \\
\hline Gesag & A6 & 12,6 & 2,9 & 13,0 & 3,0 \\
\hline Outonomie & A7 & 13,5 & 2,7 & 14,3 & 3,0 \\
\hline Kreatiwiteit & $\mathrm{C} 1$ & 13,7 & 3,9 & 14,0 & 3,6 \\
\hline Kulturele identiteit & $\mathrm{C} 2$ & 15,2 & 2,9 & 13,8 & 3,3 \\
\hline Finansiële vergoeding & E1 & 16,0 & 2,6 & 16,4 & 3,2 \\
\hline Finansiële sekuriteit & E2 & 17,6 & 2,2 & 17,6 & 2,5 \\
\hline Eie lewenstvl & $\mathrm{L}$ & 14,5 & 2,4 & 15,0 & 2,7 \\
\hline Persoonlike ontwikkeling & P1 & 18,0 & 1,7 & 18,1 & 2,2 \\
\hline Fisiese aktiwiteite & P2 & 13,6 & 3,3 & 14,6 & 3,5 \\
\hline Liggaamlike vaardigheid & P3 & 9,5 & 3,3 & 10,2 & 2,9 \\
\hline Status & P4 & 14,5 & 2,7 & 14,7 & 2,8 \\
\hline Risiko & $\mathrm{R}$ & 9,5 & 3,3 & 10,9 & 3,7 \\
\hline Sosiale interaksie & S1 & 14,1 & 3,3 & 14,1 & 2,9 \\
\hline Sosiale verhoudings & S2 & 15,7 & 2,9 & 15,6 & 3,1 \\
\hline Geestelikheid & S3 & 16,3 & 2,6 & 15,4 & 3,1 \\
\hline Verskeidenheid & V & 13,5 & 2,8 & 14,0 & 2,6 \\
\hline Aangename werksomstandighede & W & 14,6 & 2,6 & 14,2 & 3,2 \\
\hline
\end{tabular}

TABEL 2

F-OM-IN-TE-SLUIT-WAARDES VIR ELKE SUBSKAAL VOORDAT ENIGE SUBSKALE IN DIE EERSTE DISKRIMINANT-FUNKSIE INGESLUIT IS

\begin{tabular}{cc}
\hline Veranderlikes & F-om-in-te-sluit-waardes \\
\hline A1 & 5,291 \\
A2 & 3,835 \\
A3 & 0,565 \\
A4 & 2,749 \\
A5 & 0,291 \\
A6 & 0,679 \\
A7 & 2,931 \\
C1 & 0,445 \\
C2 & $10,521^{\star *}$ \\
E1 & 0,715 \\
E2 & 0,044 \\
L & 1,510 \\
P1 & 0,092 \\
P2 & 3,595 \\
P3 & 2,312 \\
P4 & 0,244 \\
R & 8,225 \\
S1 & 0,043 \\
S2 & 0,043 \\
S3 & 5,654 \\
V & 1,248 \\
W & 1,387 \\
\hline
\end{tabular}

Grade van vryheid $=1$ en 206

${ }^{\star *} \mathrm{p}<0,01$

In die daaropvolgende stappe van die diskriminantontleding word die F-om-in-te-sluit-waardes vir die oorblywende veranderlikes telkens weer bereken nadat die veranderlike met die grootste F-waarde in die diskriminantfunksie ingesluit is. Die volgende veranderlikes is ingesluit: Kulturele identiteit,
Estetika, Vermoë benutting, Risiko, Finansiële vergoeding, Persoonlike ontwikkeling en Prestasie. Geen verdere veranderlike het F-waardes $\geq 3,0$ behaal nie en is gevolglik nie in die diskriminant-funksie ingesluit nie. Genoemde veranderlikes kon gevolglik in kombinasie beduidend tussen die beroepsrealistiese en beroepsonrealistiese subgroepe onderskei, maar word nie in volgorde van belangrikheid geïdentifiseer nie.

In Tabel 3 verskyn die getal gevalle van die ondersoekgroep wat in elke subgroep geklassifiseer is, asook die persentasie korrekte klassifikasies.

TABLE 3

DIE GETAL KLASSIFIKASIES PER GROEP EN DIE PERSENTASIE KORREKTE KLASSIFIKASIES MET BEHULP VAN DIE KLASSIFIKASIEFUNKSIES

\begin{tabular}{lccc}
\hline \multirow{2}{*}{ Groep } & \multicolumn{2}{c}{$\begin{array}{c}\text { Getal gevalle in groep } \\
\text { geklassifiseer }\end{array}$} & $\begin{array}{l}\text { \% korrek } \\
\text { geklassifiseer }\end{array}$ \\
\cline { 2 - 3 } & $\begin{array}{c}\text { Beroeps- } \\
\text { realisties }\end{array}$ & $\begin{array}{c}\text { Beroeps- } \\
\text { onrealisties }\end{array}$ & \\
\hline Beroepsrealisties & 93 & 35 & 72,66 \\
Beroepsonrealisties & 28 & 52 & 65,00 \\
\hline Totaal & 121 & 87 & 68,83 \\
\hline
\end{tabular}

Dit blyk uit Tabel 3 dat $73 \%$ van die beroepsrealistiese en $65 \%$ van die beroepsonrealistiese subjekte korrek geklassifiseer is nadat die afgeleide klassifikasiefunksies op die routellings toegepas is. Dit dui daarop dat ' $n$ ongeklassifiseerde subjek se vlak van beroepsrealisme met ' $n$ redelike mate van sekerheid met behulp van die verkreë klassifikasiefunksies voorspel kan word.

'n J-uitsnitklassifikasie is ook bereken om ' $n$ aanduliding van die bruikbaarheid van die klassifikasiefunksie te verkry. In die J-uitsnit klassifikasie is elke geval in 'n groep geklassifiseer volgens die klassifikasiefunksie wat bereken is uit al die data, uitgesonderd die data van die geval wat geklassifiseer is. Die resultate het presies ooreengestem met dié wat in Tabel 3 verskyn.

\section{BESPREKING EN GEVOLGTREKKINGSS}

Dit blyk (Tabel 3) dat bykans 69\% van die totale ondersoekgroep korrek geklassifiseer is nadat die verkreë klassifikasiefunksies volgens die lineêre diskriminantfunksie op die beskikbare data toegepas is. Die gevolgtrekking kan dus gemakk word dat die mate van realisme waarmee die beroepskeuseproses deur die ondersoekgroep benader is, met ' $n$ redelike mate van sekerheid bepaal kon word op grond van hulle routellings soos behaal op die genoemde sewe subskale van die Waardeskaal.

Dipboye en Anderson (in Osipow, 1983) kon geen beduidende verskille ten opsigte van waarde-oriëntasie by beroepseker en beroepsonseker adolessente identifiseer nie. Die resultate van hierdie ondersoek stem derhalve nie met dié van bogenoemde navorsers ooreen nie. Die mees voor die handliggende verklaring vir die verskillende gevolgtrekkings is waarskynlik die gebruik van 'n meerveranderlike statistiese tegniek in die onderhawige studie, teenoor enkelveranderlike metodes deur Dipboye en Anderson.

Uit die navorsing van Shertzer (1985) blyk dit dat adolessente uit laer sosio-ekonomiese groepe geneig is om materiële waardes hoër te ag by die keuse van 'n loopbaan, terwyl adolessente uit hoër statusgroepe beroepskeuses oorweeg wat selfverwesenliking en arbeidstevredenheid in die hand werk. Die ondersoekgroep in hierdie studie was redelik homogeen verteenwoordigend van die hoër sosio-ekonomiese statusgroep, gevolglik bied die feit dat die totale groep (m.a.w. on- 


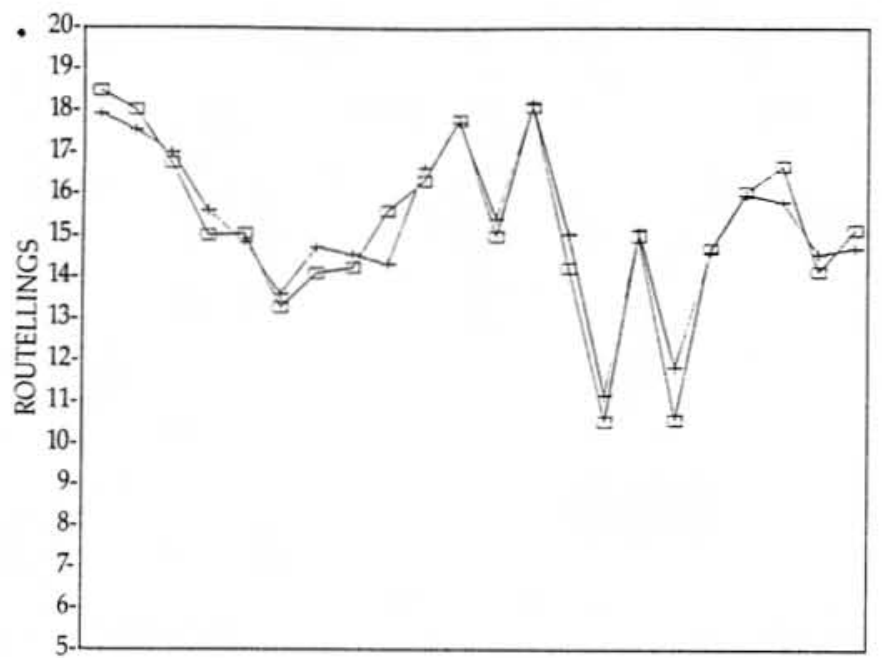

A1 A2 A3 A4 A5 A6 A7 C1 C2 E1 E2 L P1 P2 P3 P4 R S1 S2 S3 V W WAARDESKAAL

$$
=\text { Realisties }
$$

Figuur 1: Gemiddelde routellings op die Waardeskaalsubskale van beroepsrealistiese en beroepsonrealistiese

geag subgroepverdeling) voorkeur verleen het aan waardes soos Vermoëbenutting, Persoonlike ontwikkeling en Prestasie, bevestiging vir die bevindings van Shertzer (1985).

Die 22 subskale van die Waardeskaal kan in terme van ses onderliggende konstrukte saamgevat word (Langley et al., 1992). Indien die verkreë waarde-verskille tussen die beroepsrealistiese en beroepsonrealistiese groepe in terme van hierdie ses faktore geinterpreteer word, blyk die volgende tendense na vore te kom: die waarde-voorkeure van die realistiese groep kan binne een faktor nl., "innerlik georiënteerde waardes" (intrinsieke waardes) gegroepeer word, terwyl die onrealistiese groep se waarde-voorkeure oor vier verskillende faktore (Innerlike oriëntasie, Materialisme, Outonome lewenstyl en Humanisme) verspreid was. Dit blyk dus dat die beroepsrealistiese groep, wat waarde-voorkeure betref, 'n meer homogene ontwikkelingspatroon getoon het, terwyl die beroepsonrealistiese groep ' $n$ meer gedifferensieerde patroon geopenbaar het. Hierdie bevinding sluit aan by Super (1980) se konstruk van loopbaanvolwassenheid, aangesien intrinsieke waarde-voorkeure (volgens Super) saam met interne lokus van kontrole, positiewe selfkonsep en toekomsgerigtheid 'n belangrike rol in loopbaanvolwassenheid en realistiese beroepsbesluitneming speel.

Die resultate van hierdie studie kan ook gesien word as bevestigend van die teorie van Katz (1963) waarvolgens ' $n$ individu se waardesisteem ' $n$ belangrike oortuigingskrag by realistiese beroepsbesluitneming vorm.

In ooreenstemming met Zunker (1990) word aanbeveel dat die taksering en integrasie van die waarde-oriëntasies van kliënte tydens die beroepsvoorligtingsproses as ' $n$ belangrike prioriteit beskou behoort te word. In hierdie verband kan die Waardeskaal as 'n psigometriese tegniek nuttig aangewend word.

\section{ERKENNING}

Dr JDM Hanekom, voorheen dosent aan die Dept. Sielkunde, Universiteit van Stellenbosch word bedank vir sy betrokkenheid by hierdie navorsingsprojek.

\section{VERWYSINGSLYS}

Büchner, C.B. (1971). Die stabiliteit van die toekomsplanne van 'n generasie standerd X-leerlinge. Ongepubliseerde meesterstesis, Universiteit van Port Elizabeth.

Crites, J.O. (1981). Career counselling: Models, methods and materials. New York: McGraw-Hill.

Fredrickson, R.H. (1982). Career information. Englewood Cliffs, New Jersey: Prentice-Hall.

Handleiding vir die KODUS-belangstellingsvraelys (1984). Kaaplandse Onderwysdepartement \& Universiteit van Stellenbosch.

Kanchier, C., \& Unruh, W.R. (1989). Work values: How do managers who change jobs differ from those who do not? Journal of Employment Counseling, 26, 107-115.

Katz, M. (1963). Decisions and values: A rationale for secondary school guidance. New York: College Entrance Examination Board.

Klecka, W.R. (1986). Discriminant analysis. Beverly Hills: Sage Publications.

Kohlberg, L. (1980). Stages of moral development: as a basis for education. In B. Munsey (red.). Moral developinent, moral education, and Kohlberg. Birmingham, Ala.: Religious Education Press.

Kotzé, M.E. (1993). Die verband tussen loopbaanvolwassenheid, rolbelangrikheid en akademiese prestasie: 'n verkennende studie. Tydskrif vir Bedryfsielkunde, 19, 13-17.

Kroll, A.M., Dinklage, L.B., Lee, J., Morley, E.D., \& Wilson, E.H. (1970). Career development: Growth and crisis. New York: John Wiley \& Sons.

Langley, R., du Toit, R., \& Herbst, D.L. (1992). Handleiding vir die Waardeskaal. Pretoria: Raad vir Geesteswetenskaplike Navorsing.

Lindhard, N., \& Africa, H. (1982). Beroepe te kus en te keur: Loopbaanopvoeding in die klaskamer. Kaapstad: Longman Penguin.

Naicker, A. (1994). The psycho-social context of career counseling in South African Schools. South African Jou mal of Psychology, 24, 27-34.

Osipow, S.H. (1983). Theories of career development. New York: Appleton-Century-Crofts.

Plug, C., Meyer, W.F., Louw, D.A., \& Gouws, L.A. (1986). Psigologiewoordeboek. Johannesburg: McGraw-Hill.

Rounds, J.B. (1990). The comparative and combined utility of work value and interest data in career counseling with adults. Journal of Vocational Behavior, 37, 32-43.

Shertzer, B. (1985). Career planning: Freedom to choose. Boston: Houghton Mifflin.

Super, D.E. (1980). A life-span, life-space approach to career development. Journal of Vocational Behavior, 16, 282-296.

Tolbert, E. L. (1980). Counseling for career development. Boston: Houghton Mifflin.

Vondracek, F.W., Shimizu, K., Schulenberg, J., Hostetler, M., \& Sakayanagi, T. (1990). A comparison between American and Japanese students' work values. Journal of Vocational Behavior, 36, 274-285.

Whiteley, J.M., \& Resnikoff, A. (1978). Career counseling. Monterey: Brooks/Cole.

Zunker, V.G. (1990). Career counseling: Applied concepts of life planning. Pacific Grove, California: Brooks/Cole. 